\title{
PROCESSING MODIFIER-HEAD AGREEMENT IN LONG FINNISH WORDS: EVIDENCE FROM EYE MOVEMENTS*
}

\author{
SEPPO VAINIO ${ }^{\mathrm{a}}$ - RAYMOND BERTRAM ${ }^{\mathrm{a}}$ - ANNELI PAJUNEN ${ }^{\mathrm{b}}$ - \\ JUKKA HYÖNÄ ${ }^{\mathrm{a}}$ \\ ${ }^{\mathrm{a}}$ University of Turku, Finland \\ ${ }^{\mathrm{b}}$ University of Tampere, Finland
}

Corresponding author: Raymond Bertram, address: Department of Psychology, University of Turku, FIN-20014, e-mail: rayber@utu.fi

\begin{abstract}
The present study investigates whether processing of an inflected Finnish noun is facilitated when preceded by a modifier in the same case ending. In Finnish, modifiers agree with their head nouns both in case and in number and the agreement is expressed by means of suffixes (e.g., vanha/ssa talo/ssa 'old/in house/in' $\rightarrow$ 'in the old house'). Vainio et al. $(2003 ; 2008)$ showed processing benefits for this kind of modifier-head agreement, when the head nouns were relatively short. However, the effect showed up relatively late in the processing stream, such that word $n+1$, the word following the target noun talo/ssa, was read faster when it was preceded by an agreeing modifier (vanha/ssa) than when no modifier was present. This led Vainio et al. to the conclusion that agreement exerts its effect at a later stage, namely at the level of syntactic integration and not at the level of lexical access. The current study investigates whether the same holds when head nouns are considerably longer (e.g., kaupungin/talo/ssa 'city house/in' $\rightarrow$ 'in the city hall'). Our results show that the effect of agreement is facilitative in case of longer head nouns as well, but-in contrast to what was found for shorter words - the effect not only appeared late, but was also observed in earlier processing measures. It thus seems that, in processing long words, benefits related to modifier-head agreement are not confined to post-lexical syntactic integration processes, but extend to lexical identification of the head.
\end{abstract}

Keywords: agreement, Finnish, morphology, sentence comprehension, eye movements

* This study was financially supported by a grant of the Academy of Finland to the second author (Grant \#118404). 


\section{Introduction}

The present study examines the effects of grammatical agreement in reading relatively long Finnish words in a sentence context. Our aim was to study whether word length regulates the time course of the processing of grammatical agreement by comparing the results of the current study with those of previous studies (Vainio et al. 2003; 2008), in which processing of grammatical agreement was studied for relatively short words.

The term agreement refers to the linguistic phenomenon of how word forms are grammatically dependent on each other (e.g., the boy walks vs. the boys walk). There are many forms of agreement, such as subjectverb agreement, modifier-head agreement, possessive-head agreement, verb-object agreement, gender agreement and number agreement. In the present study, we deal with modifier-head agreement (hereafter referred to as MHA).

Several methods have been used to study the effects of grammatical agreement, and these methods can be divided into two general classes: reaction time (RT) methods and on-line methods. The RT methods include a maze task (a modified word-by-word paradigm, Nicol et al. 1997), naming (Guillelmon-Grosjean 2001) and lexical decision (Gurjanov et al. 1985; Lukatela et al. 1987; Schriefers et al. 1998), whereas on-line methods include the registration of event related brain potentials (ERP) (Coulson et al. 1998; Friederici et al. 1999; Gunter et al. 2000; Osterhout-Mobley 1995) and eye tracking studies (Deutsch-Bentin 2001; Pearlmutter et al. 1999; Vainio et al. 2003; 2008). As both Gunter et al. (2000) and Pearlmutter et al. (1999) stress, by using reaction time methods important information about the time course of agreement processing remains opaque. In contrast, on-line methods, can shed light on what happens during the processing of agreement structures and not only inform us about the end result (e.g., whether or not agreement facilitates processing).

One of the most common arrangements in previous studies has been to compare normal agreement structures to grammatically illegal structures that somehow violate modifier-head (Gurjanov et al. 1985; HyönäLindeman 1994), possessive-head (Lukatela et al. 1987), subject-verb (Coulson et al. 1998; Osterhout-Mobley 1995; Pearlmutter et al. 1999), subject-participle (Friederici et al. 1999), verb-object (MacWhinneyPléh 1997; Schriefers et al. 1998), gender (Deutsch-Bentin 2001; Gunter et al. 2000; Osterhout-Mobley 1995), or number (Bock et al. 2001) agree- 
ment. Despite its popularity, this approach is problematic as Pearlmutter et al. (1999) rightfully point out, since it is difficult to make inferences about normal language processing by using materials that are not clearly grammatical.

Perhaps not surprisingly, the results of most previous studies demonstrate reliable agreement effects in processing. For example, when a head noun is preceded by an agreeing modifier, the head is easier to process compared to a situation where the head is preceded by an illegal, non-agreeing modifier (Gurjanov et al. 1985; Hyönä-Lindeman 1994). However, it is not clear from these studies to what extent the effect can be ascribed to the agreeing modifier facilitating processing of the noun, to the non-agreeing modifier inhibiting processing of the noun, or to a combination of these two.

Vainio et al. (2003) studied the influence of modifier-head agreement (e.g., mainio/ksi orkesteri $/ k_{s i}{ }^{1} \rightarrow$ 'excellent/into orchestra/into' $\rightarrow$ 'into an excellent orchestra') and possessive agreement (e.g., meidän orkesteri/ $m m e \rightarrow$ 'our orchestra/our' $\rightarrow$ 'our orchestra') in sentence context in Finnish. To be able to tease apart the facilitatory and inhibitory components, they included a baseline condition. As they were interested in the time course of agreement effects, they used the eye-tracking method that is shown to be very informative in revealing moment-to-moment processing activities (see Rayner 1998 for a review). Vainio et al. (2003) observed a two-level pattern, in which the non-agreeing modifier inhibited and agreeing modifier facilitated the processing of the target noun compared to the no-modifier baseline condition. The effects showed up as relatively delayed effects, as the agreeing modifier condition elicited the fastest total fixation time (the sum of durations on all fixations on the word, including fixations that are directed back to the target word after it has been read at least once already) and the fewest regressions (i.e., eye movements directed backwards in the text), whereas the non-agreeing modifier condition elicited the longest total fixation time and the highest number of regressions. The effects did not show up in earlier first-pass measures such as first fixation duration or gaze duration. In other words, the effects only arose after the target noun had been read, which certified that the agreement effect was delayed. The participants processed modifier-head and possessive agreement in a similar manner, as indexed by a highly analogous pattern of results for the two types of structures.

${ }^{1}$ Throughout the article we will use the forward slash (/) to indicate morpheme boundaries.

Acta Linguistica Hungarica 58, 2011 
Similarly, Vainio et al. (2008) showed processing benefits for agreement when both modifier and head noun were in the inessive case (e.g., vanha/ssa talo/ssa 'old/in house/in' $\rightarrow$ 'in the old house'). Also here the effect showed up relatively late in the processing stream, such that word $n+1$, the word following the target noun talo/ssa, was read faster when it was preceded by an agreeing modifier (vanha/ssa) than when no modifier was present. In sum, both studies indicate that agreement exerts its effect at a later stage, which led Vainio et al. to the conclusion that the effect appears at the level of syntactic integration rather than at the level of lexical access.

One factor that has been neglected so far in the study of agreement effects is word length, although there is evidence that length significantly influences word processing. The general picture that emerges from previous studies related to word length is that, not surprisingly, long words take longer time to process than short words for both adults (JustCarpenter 1980; Rayner-McConkie 1976) and children (Hyönä-Olson 1995).

Another important finding is that readers have more difficulties to parse out long morphemes in long, morphologically complex words than short ones, since in the former case morpheme boundaries often do not reside within the foveal area and the degraded visual information on the morpheme boundary makes it harder to locate this boundary and to initiate the parsing process (Bertram et al. 2004). Bertram et al. found that readers do not benefit from an explicit segmentation cue around the constituent boundary when the first constituent is relatively short. In this case, the processing of short first-constituent compounds with a difference in vowel quality around the constituent boundary (e.g., selkä/ongelma 'back problem', with front vowel $\ddot{a}$ at the end of the first constituent and back vowel $o$ at the beginning of the second) was compared to the processing of compounds with the same type of vowels throughout the compound, e.g., katu/ooppera 'street opera'. It should be noted that - with the exception of a few loan words-Finnish front vowels $(\ddot{a}$, $\ddot{o}, y)$ do not appear in the same monomorphemic, inflected or derived words as Finnish back vowels $(a, o, u)$. However, they do appear in compound words such as selkä/ongelma. Having front vowels and back vowels in the same word thus indicates that the word in question is a compound word and having a front and back vowel around the constituent boundary provides a segmentation cue by signaling the exact location of the constituent boundary. However, in Bertram et al. (ibid.) processing times 
were exactly the same for compounds with the vowel quality segmentation cue (selkäongelma) as for compounds without such a cue (katuooppera). Bertram et al. proposed that a segmentation cue was not needed, since the initial fixation in these compounds was typically located around the constituent boundary, which meant that the boundary was in the area of high visual acuity, which in turn makes morphological parsing rather effortless. This was confirmed by the finding that the vowel quality segmentation cue speeded up the processing of words with a long first constituent. That is, words with a relatively long first constituent including a vowel quality segmentation cue (e.g., telakka/yhtiö 'shipyard company') were processed much faster (on average $114 \mathrm{~ms}$ ) than words like mansikka/olut 'strawberry beer'. This led Bertram et al. to conclude that the initial fixation needs to be located around the constituent boundary in order for parsing to proceed smoothly when there is no explicit segmentation cue. Since the initial fixation on a word like talo/ssa 'in the house' is typically around the third character, the morpheme boundary typically resides in the area of high visual acuity. However, in longer words, such as kaupingin/talo/ ssa 'in the city hall', the morpheme boundary between talo- and -ssa will be typically out of foveal reach. In this case, the benefits from having morphologically parsed a preceding modifier like vanha/ssa 'in the old' may be much larger than in the case of short head nouns where parsing is most likely a less effortful procedure.

In sum, more effortful processing for long target nouns than for short ones may cause that for long words agreement does not only facilitate post-lexical integration processes, but also participates in lexical identification as such. In other words, it may well be the case that the facilitative effect for agreement is to be observed at an earlier stage for long words than what has been found for short words. However, one may turn the argumentation around as well. That is, one can speculate that-since the processing of long words require more cognitive resources than that of short words - less processing resources are left for efficient post-lexical integration processes. In line with this kind of reasoning, one may predict that the facilitatory agreement effect observed for short words may be attenuated or disappear altogether for long words.

In the present study, we set out to study whether word length is capable of modulating effects due to agreement. We did so by constructing experimental materials and selecting experimental target words very similar to the materials of Vainio et al. (2008), except that the target nouns in our study are of considerable length (14-16 characters), whereas the 
target words in Vainio et al. were 7-8 characters long. In other words, we pitted long words preceded by an agreeing modifier against long words preceded by no modifier and investigated (a) whether there was a positive effect of agreement and (b) what the time course of such an effect would be in comparison to that observed in the Vainio et al. (2008) study. To our knowledge, there are no previous studies that have investigated whether word length affects how modifier-head agreement is processed during reading.

One question we would need to answer still is - if we are to find a facilitative agreement effect for long words - what would count as an early effect and what would count as a late effect. In order to answer that question, we first briefly explain some key details about eye movement behavior during reading. As noted above, previous eye movement research has convincingly demonstrated that that eye movements can give a good reflection of important aspects of reading behavior (see Rayner 1998 for a survey). In Figure 1, an eye movement record of an adult reader is presented for reading a two-line sentence.

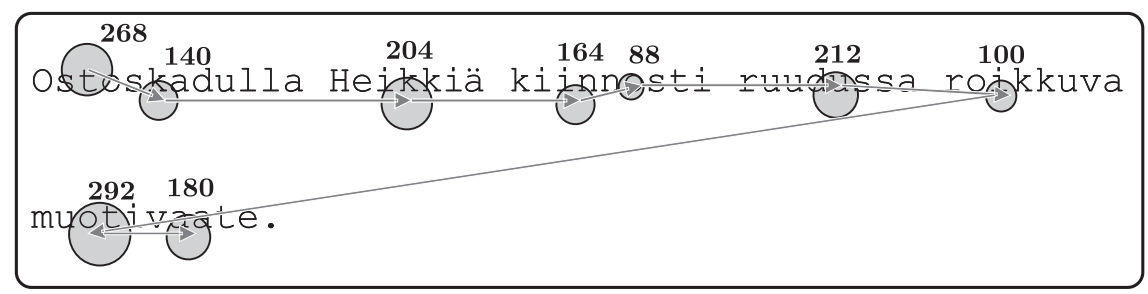

Fig. 1

An eye movement record of an adult reading a Finnish sentence. Dots represent eye fixations, while grey lines depict movements (called saccades) between two eye fixations. The number superimposed on the dot indicates the duration of the fixation in milliseconds.

Most short words typically elicit a single eye fixation on them, but longer words, such as ostos/kadu/lla ('shopping/street/in' $\rightarrow$ 'in the shopping street'), are often dealt with in two or more fixations. In contrast, short and frequent words (e.g., is or on in English) are often skipped. Fixation durations vary a lot (from less than $50 \mathrm{~ms}$ to more than 1000), but typically they are around 200 to $250 \mathrm{~ms}$. Most often the eye makes forward saccades (jumps), but about $15 \%$ of the fixations of adult readers go backwards (so-called regressions). The area around the center of fixation (about two degrees of visual angle) constitutes the foveal area, where visual acuity is highest. Under normal reading circumstances this 
area amounts to approximately 8 characters. The eye movement record provides an online protocol of the time course of processing by yielding different measures, some reflecting early lexical processing, some others reflecting later lexical or post-lexical processing.

Consider the eye movement record on two subsequent words in the sentence fragment of Figure 2 (...kaupungin/talo/ssa tavallisesti... '... in the city hall normally...') and presume that kaupungintalossa is one of our target words that in one condition is preceded by the modifier vanha/ssa 'in the old' and in another condition is not preceded by any modifier. A possible eye fixation pattern on the two words is depicted in Figure 2 by numbered circles denoting fixations and their order presented on top of the words. In this example, the imaginary reader makes an initial fixation in the beginning of the word kaupungintalossa (fixation 1), after which she makes two more fixations (fixation 2 and 3 ) on the latter part of the word, followed by two fixations (fixation 4 and 5) on the next word, tavallisesti. After that, she makes a regression (fixation 6) back to the target word in order to reinspect it.

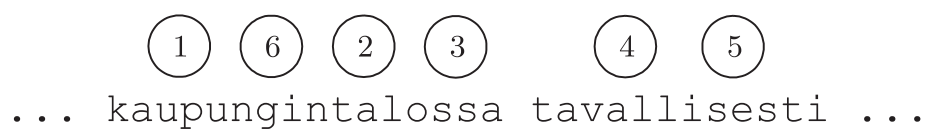

First fixation duration, target noun:

Second fixation duration, target noun:

Third fixation duration, target noun:

Gaze duration, target noun:

Rereading time, target noun:

First fixation duration, word $n+1$ :

Gaze duration word $n+1$ :
Fixation 1

Fixation 2

Fixation 3

Fixations $1+2+3$

Fixation 6

Fixation 4

Fixations $4+5$

Fig. 2

Different dependent measures extractable from the eye movement record. The duration of fixation 1 is the earliest durational measure reflecting initial lexical processing. Rereading time (duration of fixation 6) is the latest durational measure, most probably reflecting later post-lexical processes, such as syntactic integration.

Now, if there is an effect of agreement in the duration of the first fixation (Fixation 1 in Figure 2), we may conclude that agreement exerts its effect early and most probably affects lexical identification of long words, since first fixation duration is the earliest durational measure that can be extracted from the eye movement record. However, the long target words employed in the present study were 14 to 16 characters long and 
in all likelihood require at least two eye fixations in order to bring all letters within an area of high visual acuity for detailed visual inspection. In other words, we may assume that the second fixation is also needed to fully identify all letters in the word, and possible agreement effects in the second fixation duration may therefore also be taken as a relatively early effect, showing that agreement exerts an effect on lexical identification.

At this point, we should add that first and second fixation durations are not the only measures indexing early processes related to lexical identification. Also the probability of making two or three fixations indexes relatively early processes. ${ }^{2}$ That is, the "decision" to make a 2 nd fixation is made during the 1st fixation and the decision to make a $3 \mathrm{rd}$ fixation is made during the 2 nd fixation. So if there are considerably more 3rd fixations on the target word in the modifier absent condition than in the modifier present condition, this indicates that readers have decided during the second fixation that a third fixation is more often needed when there is no modifier. On the other hand, if there is no effect in 1st or 2nd fixation duration or in the probability of a 2nd or 3rd fixation, one may assume that the effect is relatively late, even if it would show up in gaze duration (the total reading time on a word before exiting it for the first time; in Figure 2, the added durations of fixation 1, 2 and 3). In this case, one has to assume that the effect can be traced to differences in the probability of 4 th or 5th fixation and/or in the duration of 3rd, 4th, or 5th fixation. A late effect is taken to reflect syntactic integration taking place after lexical identification. This is even more likely if the effect only comes alive in first fixation duration and/or gaze duration of word $n+1$ (i.e., in Figure 2, fixation 4 and fixation $4+5$, respectively) and/or rereading time (fixation 6 ). To examine the time course of processing in our study, we considered all the measures mentioned above: 1st fixation, 2nd fixation, 3rd fixation and gaze duration of the target as well as the probability of two and three fixations as well as first fixation and gaze duration of the word following the target (word $n+1$ ) and rereading time of the target word (the time spent on the target word after having exited it for the first time).

\footnotetext{
2 To anticipate what is coming, the probability of making at least one fixation was 1 , i.e., readers always made at least one fixation on our long target words.
} 


\section{Experiment}

\subsection{Method}

\subsubsection{Participants}

Twenty-two native speakers of Finnish (16 female and 6 male students of the University of Turku in the age range of 19 to 30 years) participated in the experiment. All participants had normal or corrected to normal vision.

\subsubsection{Apparatus}

Eye movements were collected by the EyeLink eyetracker manufactured by SR Research Ltd. (Canada). The eyetracker is an infrared video-based tracking system combined with hyperacuity image processing. There are two cameras mounted on a headband (one for each eye) including two infrared LEDs for illuminating each eye. The headband weighs $450 \mathrm{~g}$ in total. The cameras sample pupil location and pupil size at the rate of $250 \mathrm{~Hz}$. Registration can be done either monocularly or binocularly. The data was collected from the dominant eye, which was usually the right eye, by placing the camera and the two infrared lights $4-6 \mathrm{~cm}$ away from the eye. The resolution of eye position is 15 seconds of arc and the spatial accuracy better than 0.5 degrees. Head position with respect to the computer screen is tracked via a head-tracking camera. Four LEDs are attached to the corners of the computer screen, which are viewed by the head-tracking camera, once the participant sits directly facing the screen. Possible head motion is detected as movements of the four LEDs and is compensated for on-line from the eye position records.

\subsubsection{Materials}

Forty 14-16-characters-long Finnish nouns in the translative case (-ksi) and 40 in the inessive case $(-s s a$ or $-s s \ddot{a})$ were used as targets in the experiments. The target nouns were embedded in sentences in which they were immediately preceded either by (a) an agreeing modifier, henceforth the agreeing modifier condition; or (b) a word that was not a modifier, henceforth the modifier absent condition. Agreement was orthographically (and phonologically) transparent, as the same case ending was repeated both in the modifier and in the head in both structures. The chosen case endings are both fully productive, but inessives are more 
frequent than translatives. Translative typically encodes concrete or abstract transition or transmutation, whereas inessive typically expresses location (analogous in meaning to the English preposition in). Among the Finnish cases, inessive is located at the semantic end on the semanticgrammatical continuum, whereas translative is neither clearly semantic nor clearly grammatical. In constructing our materials we made use of a characteristic of Finnish, namely its relatively free word order. Word order is relatively free in Finnish because argument roles are marked by case inflections. Given this possibility, we decided to use a non-canonical word order in the experimental materials as our aim was to study agreement effects without the influence of the main verb. In other words, all target noun phrases appeared prior to the verb. It should be noted that non-canonical structures are less frequent in Finnish than canonical ones, but due to the extensive case-marking system they appear quite regularly and are therefore not particularly strange from a pragmatic point of view.

The head nouns in the four experimental conditions (20 translatives in the agreeing modifier condition, 20 translatives in the modifier absent condition, 20 inessives in the agreeing modifier condition, and 20 inessives in the modifier absent condition) were controlled for lemma frequency (i.e., cumulative base frequency), surface frequency (the frequency of the surface form), and word length. The frequencies of the target nouns and the type of sentences were strictly matched to those used by Vainio et al. (2008) in their Experiment 1, to be able to inspect the word length effect on agreement. The frequency measures are based on a newspaper corpus of 22.7 million word tokens (Laine-Virtanen 1999; Virtanen-Pajunen 2000). Note that since most of the words preceding the targets in the modifier absent condition were adverbs that have only one word form, the surface frequency of these words was higher than that of agreeing modifiers, but the adverbs and modifiers were matched on lemma frequency and word length. The lexical-statistical information of the target word and its preceding word $(n-1)$ is listed in Table 1.

An additional feature that was matched was the number of compound words in the four conditions, which varied between 14 and 16 across the conditions; the remaining targets were derived nouns. Also the frequencies of the compound word constituents were matched across the four conditions - see e.g., Bertram-Hyönä (2003); Hyönä et al. (2004); HyönäPollatsek (1998); Juhasz et al. (2009) for effects of constituent frequency on word processing. The target expressions were formed concatenatively (e.g., pankkikriisi + ssA $\rightarrow$ pankkikriisissä 'in the bank crisis', although in 
$65 \%$ of the targets stem-internal morpho-phonemic changes were required (e.g., palolaitos $+s s A \rightarrow$ palolaitoksessa 'in the fire department'). There were 13 (out of 20) target words containing a stem-internal morphophonemic change in the agreeing modifier condition and 14 words in the modifier absent condition for inessive; the numbers for translative were $13 / 20$ and $14 / 20$, respectively.

\section{Table 1}

Mean lemma and surface frequency (per million), mean word length in letters, and their standard deviations in parentheses for the target word $(n)$ and the word preceding the target word $(n-1)$

\begin{tabular}{|c|c|c|c|c|c|c|c|}
\hline \multirow[b]{2}{*}{ Word } & \multirow[b]{2}{*}{ Control variable } & \multicolumn{3}{|c|}{ Modifier present } & \multicolumn{3}{|c|}{ Modifier absent } \\
\hline & & Translat. & Inessive & Aver. & Translat. & Inessive & Aver. \\
\hline \multirow[t]{3}{*}{$n$} & Lemma Frequency $^{a}$ & $28(20)$ & $27(20)$ & 27 & $26(20)$ & $27(20)$ & 27 \\
\hline & Surface Frequency ${ }^{a}$ & $0.3(0.3)$ & $0.3(0.3)$ & 0.3 & $0.3(0.3)$ & $0.3(0.3)$ & 0.3 \\
\hline & Word length & $14.8(0.8)$ & $14.7(0.7)$ & 14.8 & $14.9(0.9)$ & $14.8(0.8)$ & 14.9 \\
\hline \multirow[t]{3}{*}{$n-1$} & Lemma Frequency ${ }^{a b}$ & $843(1169)$ & $5165(12683)$ & 3004 & $825(1106)$ & 1551 (1399) & 1188 \\
\hline & Surface Frequency ${ }^{a c}$ & $13(27)$ & $11(12)$ & 12 & $601(1037)$ & 1031 (1394) & 816 \\
\hline & Word length & $7.6(0.5)$ & $8.0(0.6)$ & 7.8 & $7.1(1.2)$ & $7.5(1.5)$ & 7.3 \\
\hline
\end{tabular}

${ }^{a}$ All values scaled to one million. ${ }^{b}$ There seems to be a mismatch in lemma frequency for both modifier presence and case. However, the extreme high values for the inessive case are triggered by a few outliers. Consequently, when transforming the values to log values (as one usually does in psycholinguistic research) all conditions are matched with one another. ${ }^{c}$ The mismatch in surface frequency between modifier present and modifier absent holds true also when frequency is log-transformed frequency. Any advantage for the modifier absent condition may thus be triggered by a frequency spillover effect. Hence we conducted covariate analyses with the frequency of $n-1$ as a covariate when this turned out to be the case. "Translat." = Translative, "Aver." = Average.

Each target noun phrase was embedded in a separate sentence. Two matched sentence frames were created: one in which the head noun was immediately preceded by an adjectival modifier and one in which there was no modifier; each target noun was presented once. The sentence frame in each matched pair was identical at least up to the word following the target, except for the matched target nouns; the rest of the sentence was different. To match for the semantic plausibility of the sentence frames, a rating study was conducted, in which both versions of the sentence pairs were listed underneath each other. Six participants who did not participate in the reading experiment rated the naturalness of the experimental sentences by using one of three alternatives: Sentence 1 sounds more natural, Sentence 2 sounds more natural, or Sentence 1 and 2 sound equally natural. Seventy-five percent of the sentence pairs were rated equally 
natural; for $12.5 \%$ of the pairs Sentence 1 was rated more natural than Sentence 2, while the reverse was true for the remaining $12.9 \%$. If at least three participants rated one of the sentences to be more natural than its counterpart, a new sentence frame was constructed for the word pair.

To eliminate any influence of the verb on agreement processing, the target nouns appeared prior to the verb to which the target noun phrase is attached. This non-canonical word order is not atypical in Finnish (word order serves mainly pragmatic functions, see e.g., Vilkuna 1989). An example sentence pair for both the inessive and the translative case is presented below (the target word is underlined; the morphological marking of agreement in the modifier-present version is shown in bold):

(1) Agreeing modifier condition, inessive case

Jutun mukaan pienessä palolaitoksessa tavallisesti on vain muutama palkattu henkilö.

'Story - according to - small-in - fire department-in - usually - is - only - few hired - person. $\rightarrow$ The story tells that in a small fire department there are only a few hired persons.'

(2) Modifier absent condition, inessive case

Jutun mukaan pankkikriisissä tavallisesti lainojen takaajien asema on kaikkein heikoin.

'Story - according to - bank crisis-in - usually - loans' - warrantors' - situation is - worst. $\rightarrow$ The story tells that in a bank crisis the loan warrantors' situation is usually the worst.'

(3) Agreeing modifier condition, translative case

Artikkelin mukaan rumiksi kaatopaikoiksi muuttuneet leirintäalueet olisi siivottava pikaisesti.

'Article - according to - ugly-into - dumping places-into - become - camp sites - should be - cleaned - immediately. $\rightarrow$ According to the article, the camp sites that have turned into ugly dumping places should be cleaned immediately.'

(4) Modifier absent condition, translative case

Artikkelin mukaan muistomerkeiksi muuttuneet vanhat rakennukset pitäisi puhdistaa ja kunnostaa.

'Article - according to - monument-into - become - old - buildings - should be cleaned - and - repaired. $\rightarrow$ According to the article, the old buildings that have turned into monuments should be cleaned and repaired.'

The 80 target sentences were mixed with 80 filler sentences of different grammatical structures. The target word never appeared in the beginning or end of a text line. The target sentences were presented in Courier font left-justified one at a time roughly at the center of the computer screen. 
With a viewing distance of about $65 \mathrm{~cm}$, one character space subtended approximately 0.5 degrees of visual angle. The sentences were presented in two blocks, so that the two members of each sentence pair never appeared in the same block. The order of blocks was counterbalanced across participants, and within a block the order of sentences was individually randomized.

\subsubsection{Procedure}

Prior to the experiment, the eye-tracker was calibrated using a 9-point calibration grid that extended over the entire computer screen. Prior to each sentence, the calibration was checked by presenting a fixation point on the left corner of the screen coinciding with the location of the first letter of the sentence about to be presented. If needed, the calibration was automatically corrected.

Participants were instructed to read sentences for comprehension at their own pace. They were further told that periodically they would be asked to paraphrase the last sentence they have just read to make sure that they attended to what they read. However, it was emphasized that the task was to comprehend, not to memorize the sentences. Participants were asked to paraphrase the sentence approximately after every 10th sentence. The experimental session lasted a maximum of 45 minutes.

\subsection{Results}

A $2 \times 2$ [(Modifier Type: agreeing modifier vs. modifier absent $) \times($ Case: inessive vs. translative)] ANOVA was performed on the data with both variables treated as within-participant variables in the participant analyses and modifier type as a within-item and case as a between-item variable in the item analyses. All trials were excluded where there was a track loss or where the target noun was initially skipped (i.e., not fixated during the first-pass reading). The missing data amounted to $1.5 \%$. The means and standard deviations are presented in Table 2.

\subsubsection{First, second and third fixation duration, target noun}

There was a significant main effect of modifier type for the target nouns in first fixation duration, $F_{1}(1,21)=12.14$, MSE $=209.35, p=.002$; $F_{2}(1,38)=11.16, \mathrm{MSE}=208.79, p=.002$. First fixation duration was 
$11 \mathrm{~ms}$ longer in the agreeing modifier than in the modifier absent condition, thus showing a seemingly inhibitory agreement effect. However, as mentioned earlier, there was a surface frequency difference in word $n-1$ favoring the modifier absent condition. Therefore we used a covariate analysis to exclude a possible spill-over effect of frequency (see also Vainio et al. 2008). This analysis showed that the inhibitory agreement effect was no longer reliable (both $p \mathrm{~s}>.115$ ). Also the main effect of case and the Modifier Type times Case interaction were non-significant (all $p \mathrm{~s}>.10$ ). For the second and third fixation duration no effect was significant (all $p \mathrm{~s}>.10$ ).

\subsubsection{Gaze duration, target noun}

In gaze duration (sum of all first-pass fixations until leaving the word), there was a significant main effect of modifier type for the target nouns, $F_{1}(1,21)=17.88, \mathrm{MSE}=2268.84, p<.001 ; F_{2}(1,38)=3.81, \mathrm{MSE}=$ $9176.45, p=.058$. Gaze duration was $43 \mathrm{~ms}$ shorter (548 ms vs. $591 \mathrm{~ms}$ ) in the modifier present than in the modifier absent condition. The main effect of case was significant in the participant but not in the item analyses, $F_{1}(1,21)=6.55, \mathrm{MSE}=3898.45, p<.02 ; F_{2}(1,38)=1.83, p=$ .18. There was a tendency for translatives to be read faster than inessives $(35 \mathrm{~ms})$. The Modifier Type $\times$ Case interaction did not approach significance (both $F \mathrm{~s}<1$ ).

\subsubsection{Rereading time, target noun}

In rereading time of the target noun (time spent on the target noun after having exited it for the first time), there was neither a significant main effect of modifier type nor a Modifier Type $\times$ Case interaction. The main effect of case was significant in the participant but not in the item analyses, $F_{1}(1,21)=8.37, \mathrm{MSE}=1490.70, p=.009 ; F_{2}(1,38)=$ $3.16, \mathrm{MSE}=3661.36, p=.084$; target nouns in the translative case were on average reread for $24 \mathrm{~ms}$ longer than those in the inessive case (74 vs. $50 \mathrm{~ms}$, respectively). There was also evidence for a higher probability of rereading translatives in comparison to inessives (18.3\% vs. 12.6 $\%), F_{1}(1,21)=4.06, \mathrm{MSE}=0.007, p=.057 ; F_{2}(1,38)=4.38, \mathrm{MSE}=$ $0.014, p=.043$. Taken together, it is hard to say which constructions are easier to process, with slight advantage for translatives in a measure on the target noun itself and slight advantage for inessives in later measures. 


\section{Table 2}

Average durations, probabilities and locations of fixations, as a function of modifier presence and case for target word $n$ and the word following the target word $(n+1)$

\begin{tabular}{|c|c|c|c|c|c|c|c|}
\hline \multirow[b]{2}{*}{ Word } & \multirow[b]{2}{*}{ Measure } & \multicolumn{3}{|c|}{ Modifier present } & \multicolumn{3}{|c|}{ Modifier absent } \\
\hline & & Translat. & Inessive & Aver. & Translat. & Inessive & Aver. \\
\hline \multirow[t]{12}{*}{$n$} & First fixation duration & $205(23)$ & $209(25)$ & 207 & $197(21)$ & $195(27)$ & 196 \\
\hline & Second fixation duration & $191(24)$ & $189(28)$ & 190 & $191(27)$ & $198(25)$ & 195 \\
\hline & Third fixation duration & $186(36)$ & $185(32)$ & 186 & $193(35)$ & $193(35)$ & 193 \\
\hline & Gaze Duration & $530(147)$ & $566(144)$ & 548 & $574(113)$ & $607(162)$ & 591 \\
\hline & Rereading Time & $80(69)$ & $62(37)$ & 71 & $68(53)$ & $39(48)$ & 54 \\
\hline & $\begin{array}{l}\text { Probability of } 2 \\
\text { or more fixations }\end{array}$ & $0.89(0.10)$ & $0.91(0.09)$ & 0.90 & $0.95(0.05)$ & $0.96(0.06)$ & 0.96 \\
\hline & $\begin{array}{l}\text { Probability of } 3 \\
\text { or more fixations }\end{array}$ & $0.53(0.22)$ & $0.55(0.22)$ & 0.54 & $0.66(0.19)$ & $0.65(0.25)$ & 0.66 \\
\hline & $\begin{array}{l}\text { Probability of } 4 \\
\text { or more fixations }\end{array}$ & $0.18(0.18)$ & $0.23(0.19)$ & 0.20 & $0.22(0.18)$ & $0.29(0.22)$ & 0.25 \\
\hline & Probability of rereading & $0.19(0.15)$ & $0.15(0.09)$ & 0.17 & $0.17(0.09)$ & $0.10(0.09)$ & 0.14 \\
\hline & First fixation location & $5.21(1.16)$ & $4.99(1.22)$ & 5.10 & $4.89(1.04)$ & $4.80(0.98)$ & 4.85 \\
\hline & Second fixation location & $9.54(1.14)$ & $9.01(1.33)$ & 9.28 & $9.07(1.44)$ & $8.95(1.25)$ & 9.01 \\
\hline & Third fixation location & $8.99(1.21)$ & $9.82(1.24)$ & 9.41 & $9.54(1.03)$ & $8.92(1.29)$ & 9.23 \\
\hline \multirow[t]{2}{*}{$n+1$} & First fixation duration & $206(40)$ & $200(36)$ & 203 & $222(32)$ & $206(39)$ & 214 \\
\hline & Gaze duration & $258(74)$ & $259(63)$ & 259 & $288(78)$ & $277(76)$ & 283 \\
\hline
\end{tabular}

\subsubsection{Probability of two or more and three or more fixations, target noun}

A significant main effect of modifier type emerged in the probability of making at least two fixations on the target nouns, $\mathrm{F}_{1}(1,21)=$ $10.86, \mathrm{MSE}=.007, p<.01 ; F_{2}(1,38)=10.00, \mathrm{MSE}=.007, p<.01$. This probability was 0.06 less in the agreeing modifier (0.90) than in the modifier absent condition (0.96), thus showing that people more often decided during the 1st fixation to make a 2 nd fixation on the target noun when no modifier was present than when the noun was preceded by an agreeing modifier. Similarly, the probability of at least three fixations was smaller $(0.12)$ in the agreeing $(0.54)$ than in the no modifier $(0.66)$ condition, $F_{1}(1,21)=53.66, \mathrm{MSE}=.005, p<.001 ; F_{2}(1,38)=14.18, \mathrm{MSE}=$ $.018, p=.001$, a difference reflecting processing done during the $2 \mathrm{nd}$ fixation. In sum, the probability analyses show that the effect of agreement comes alive rather early, at the latest during the second fixation made on the head noun. 


\subsubsection{Location of 1st, 2 nd and 3rd fixation}

We also analyzed the location of the first, second and third fixation as a function of modifier presence, but these analyses did not yield any additional insights. There was an inhibitive agreement effect in first fixation location, probably triggered by the frequency difference in $n-1$, and no agreement effects in second and third fixation location. The averages are listed in Table 2 .

\subsection{Time course analysis of the gaze duration effect}

In the current experiment, we found, as noted above, a gaze duration effect of $43 \mathrm{~ms}$ in favor of the agreeing modifier condition. The size of the gaze duration effect can be broken down into effect sizes for individual fixations. On a first thought, one may be tempted to consider the effect sizes of individual fixation durations only, but - as we argued above-a reader does not only 'decide' how long (s)he stays at a certain position in the word, but also whether the word should be refixated or whether a saccade to a subsequent word should be executed. In other words, the probability of making an $n$th fixation on the word should also be taken into account when estimating the relative time course of the gaze duration effect.

Bertram et al. (2004) developed a formula to estimate the relative time course of effects observed in gaze duration on long words typically producing several fixations on them. The formula takes into account the effect for each fixation duration, but it also considers the probabilities of fixations, for reasons given above. Transforming the formula for the current experiment, it reads as follows:

\footnotetext{
Effect size at fixation $n=\operatorname{ProbFixMod}_{n} *\left(\right.$ FixDurNoMod $_{n}-$ FixDurMod $\left._{n}\right)+$ FixDurNoMod $_{n} *\left(\operatorname{ProbFixNoMod}_{n+1}-\operatorname{ProbFixMod}_{n+1}\right)$
}

For a detailed explanation of this formula, an interested reader should consult Bertram et al. (2004). What is important here is that when we fill in the $n$ (fixation number) in the formula, we find that the size of the agreement effect on the first fixation is $1 \mathrm{~ms}$, on the second fixation it is $26 \mathrm{~ms}$, on the third fixation it is $13 \mathrm{~ms}$, and on the fourth fixation it is $3 \mathrm{~ms}$, altogether $43 \mathrm{~ms}$ constituting the overall gaze duration effect. Even though this is a rough estimate, it indicates that the bulk of the gaze duration effect can be led back to the second fixation, indicating that 
agreement exerts its influence rather early, at least at a stage in which lexical identification is not completed.

In the final section we will assess whether the agreement effect spills over to the next word as well. If an agreement effect is to be found there, we may conclude that - as for short words - agreement has a role to play in post-lexical syntactic integration as well.

\subsection{The word following the target $(n+1)$}

The word $n+1$ analysis is based on $29 n+1$ word pairs that were identical in the two conditions (14 in the inessive condition and 15 in the translative condition); the rest of $n+1$ words were long words that were broken down into two lines. Nonetheless, using all $n+1$ stimuli in the analysis yielded exactly the same results as the ones presented below.

\subsubsection{First fixation duration, word $n+1$}

A significant main effect of modifier type emerged in first fixation duration on the word following the target noun, $F_{1}(1,21)=11.38$, MSE $=$ $304.47, p=.003 ; F_{2}(1,27)=7.55, \mathrm{MSE}=333.54, p=.011$. First fixation duration was $11 \mathrm{~ms}$ (203 ms vs. $214 \mathrm{~ms}$ ) shorter in the agreeing modifier than in the modifier absent condition. The main effect of case and the Modifier Type $\times$ Case interaction were not significant (all $p \mathrm{~s}>.10$ ).

\subsubsection{Gaze duration, word $n+1$}

There was a significant main effect of modifier type in gaze duration for the word following the target noun, $F_{1}(1,21)=12.45$, MSE $=$ $784.53, p=.002 ; F_{2}(1,27)=7.14, \mathrm{MSE}=1015.68, p=.013$. Gaze duration was $24 \mathrm{~ms}$ (259 ms vs. $283 \mathrm{~ms}$ ) shorter in the agreeing modifier condition than in the modifier absent condition. The main effect of case and the Modifier Type $\times$ Case interaction were not significant (all $p \mathrm{~s}>.10)$.

\section{Discussion}

To summarize, we observed a very early inhibitory agreement effect (indexed by first fixation duration on the target), which was apparently caused by the surface frequency difference of word $n-1$. The facilitatory 
agreement effect was not present in second and third fixation duration, but appeared in the probability of making a second and third fixation on the head noun, indicating that the effect of agreement comes alive earlier in long words than in short words (Vainio et al. 2003; 2008). This was also reflected in gaze duration; gaze durations were on average $43 \mathrm{~ms}$ shorter when the target noun was preceded by an agreeing modifier than when no modifier was present. More precise calculations of effect sizes per individual fixation indicated that the bulk of the gaze duration effect can be led back to the second fixation, indicating that the effect is rather early and that for long words agreement is part and parcel of the lexical identification process. In addition, the first fixation and gaze duration of word $n+1$ was also shorter for long words preceded by an agreeing modifier than for long words with no preceding modifier (see Vainio et al. 2008 for an analogous effect obtained for short head nouns). We interpret these late effects to reflect syntactic integration.

It thus seems that the effect of modifier-head agreement is more pervasive for long than short words. This is supported by the size of the agreement effect when considering the processing of word $n$ and word $n+1$. More precisely, the effect size in gaze duration for short words in Experiment 1 of Vainio et al. (2008) (an experiment that, apart from the target words, is identical to the current experiment) was a non-significant, reversed effect of $17 \mathrm{~ms}$ on word $n$ and a significant $24 \mathrm{~ms}$ positive effect on word $n+1$, taken together an effect size of $7 \mathrm{~ms}(-17+24)$ only. For long words we found an effect of $43 \mathrm{~ms}$ on word $\mathrm{N}$ and exactly the same effect size as for short words on word $n+1$, namely $24 \mathrm{~ms}$, an effect size of $67 \mathrm{~ms}$ altogether. It thus seems clear that processing benefits related to modifier-head agreement become larger the longer the head of the noun phrase is. We argue that the reason for this is that agreement in long words does not only facilitate syntactic integration, but also lexical identification. In the following we provide a more detailed account for both facilitation processes.

With respect to lexical identification, we argued in section $\mathbf{1}$ that long words come with more effortful processing, that parsing out the suffix in long words may be more troublesome than in short words, and that both of these phenomena may alter the role of agreement in modifier-head processing. With respect to the former, we noted that it typically takes longer to retrieve a long word from lexical memory than a short word, for both adults (Just-Carpenter 1980; Rayner-McConkie 1976) and children (Hyönä-Olson 1995). Also when comparing our study with Vainio et al.'s 
(2008) first experiment, we see that the short target nouns there were processed much faster than the long target words in this study (which were tightly matched on surface and lemma frequency with the short words of Vainio et al. 2008). That is, gaze durations for the long words in our study were on average $275 \mathrm{~ms}$ longer than the short words in Vainio et al. (570 ms and $295 \mathrm{~ms}$, respectively). In other words, since lexical identification takes longer for long than for short words, there is simply more time for agreement to exert its influence on identification processes.

With respect to the second issue, we argued in the Introduction that due to the fact that the location of first fixation on the head noun is relatively far from the suffix or the morpheme boundary between the word stem and suffix, modifier-head agreement is likely to exert a greater effect in long than in short words. The average length of our target words was about 15 characters and the initial fixation location was typically around the fifth character, which would mean that the morpheme boundary before the inflectional suffix (that is, before the inessive or translative suffix) typically resides about 7 to 8 characters from the initial fixation location. We reported that the bulk of the effect is observed during the second fixation. However, even the second fixation is most often located around the ninth character which is 3 to 4 or even more characters away from the morpheme boundary before the inflectional suffix. This leads to a situation in which the morpheme boundary or the letters around the morpheme boundary are often not in sharp foveal vision and therefore not always fully identifiable. In this situation it may be important to decrease uncertainty about the identity of the letters spanning the morpheme boundary and for the parser to get a clear cue as to where the morpheme boundary resides. We propose that this cue is provided by the agreeing modifier immediately preceding the head. That is, if a modifier ends in an inessive or translative case ending, the following noun is necessarily in the same case ending. Also, when the case ending is a translative or an inessive, the form of the case ending is the same in the modifier as in the noun: both case endings always consist of three characters and the characters are exactly the same in the translative (always $-k s i$ ) and practically the same in the inessive (the only variation there being in the last vowel, which may appear as a front vowel -ssä or a back vowel -ssa, depending on the phonological properties of the stem). In other words, we argue that, in the case of long words, the modifier diminishes the uncertainty as regards the suffix of the head noun, which speeds up the morphological parsing process. To put it in another way, when there is no 
modifier it is unclear what the case ending will be at the end of the word (or even whether there is a case ending at all), which also introduces uncertainty as to how long the case ending will be. This arguably will slow down the morphological parsing process. Note that this explanation assumes that morphological parsing and recognition via morphemes is a standard procedure for inflected and/or long, morphologically complex word forms. This assumption is grounded in empirical evidence stemming from numerous studies on processing morphologically complex words in Finnish (e.g, Bertram-Hyönä 2003; Laine et al. 1995; 1999; LehtonenLaine 2003; Lehtonen et al. 2009; Niemi et al. 1994).

On top of the gaze duration effect on the head noun, we also found a late agreement effect on word $n+1$ that was exactly the same in size (24 ms) as the one that was found by Vainio et al. (2008) in their Experiment 1. Similarly to Vainio et al., we take this as evidence for the view that modifier-head agreement facilitates syntactic integration in the case of long head nouns as well. There are two types of integration that one can think of. Firstly, the modifier needs to be integrated with the noun. Secondly, the syntactic function of the noun phrase (including modifier and head) has to be determined and integrated in the sentence representation.

With respect to the former, the modifier needs to be integrated with the noun to form a syntactic unit as well as the word meanings of the modifier and noun need to be integrated to determine the meaning of the whole phrase. This kind of within-phrase integration is arguably an effortless process when the modifier and the head contain a functionally and formally identical suffix. However, on the basis of the present study, we cannot ascribe the late agreement effect to within-phrase syntactic integration. This is because in the no-modifier condition there was no need for integration, as the preceding adverb and the target noun did not belong to the same phrase. On the other hand, in their Experiment 3, Vainio et al. (2008) made use of a number of indeclinable modifiers that exist in Finnish (e.g., pikku aitio/on 'into a small balcony') and pitted these constructions against modifier-head constructions with normal case-inflected modifiers (e.g., piene/en aitio/on 'into a small balcony'). ${ }^{3}$ Also here they found a (late) effect of modifier-head agreement, such

${ }^{3}$ Pikku and pieni have the same meaning ('small'), but the former word is indeclinable, whereas the latter is not. It should be noted though that also indeclinable modifiers signal that a head will immediately follow. However, they do not signal the morphological form and with that the syntactic status of the subsequent head. 
that heads preceded by a case-inflected modifier elicited shorter rereading times than heads preceded by an indeclinable modifier, pointing to a smoother modifier-head integration for the former than for the latter type of constructions.

We suspect that the late agreement effect obtained in the present study reflects the second type of integration, that is, more effortless integration of the noun into the unfolding sentence representation when there was an agreeing modifier preceding the noun in comparison to cases when there was no such modifier. That is, the case-inflected modifier provides a cue about the syntactic function of the upcoming noun. This role is then confirmed when the noun is subsequently identified. Typically, syntactic integration of phrases takes place at phrase boundaries, in this case after the head noun. We suspect that the duplication of the suffix of a modifier-head construction gives an extra boost to the activation of the syntactic properties of the noun phrase and hence allows for a faster integration process than when the syntactic function of the noun phrase is encapsulated in one suffix only.

At any rate, the current study provides clear evidence that an agreeing modifier speeds up the processing of a subsequent noun. In that, it is in line with a great number of studies, most of them in other languages than Finnish, demonstrating facilitation in written language processing due to grammatical-syntactic agreement (e.g., Coulson et al. 1998; Friederici et al. 1999; MacWhinney-Pléh 1997; Osterhout-Mobley 1995; Pearlmutter et al. 1999; Schriefers et al. 1998; Vainio et al. 2003; 2008). The current observations are therefore far from being language-specific. Rather, they show that competent adult readers use all the possible cues present in a language to make language processing as fast and efficient as possible.

\section{References}

Bertram, Raymond-Jukka Hyönä 2003. The length of a complex word modifies the role of morphological structure: Evidence from eye movements when reading short and long Finnish compounds. In: Journal of Memory and Language 48:615-34.

Bertram, Raymond - Alexander Pollatsek - Jukka Hyönä 2004. Morphological parsing and the use of segmentation cues in reading Finnish compounds. In: Journal of Memory and Language $51: 325-45$.

Bock, Kathryn-Kathleen M. Eberhard-Cooper Cutting-Antje S. Meyer-Herbert Schriefers 2001. Some attractions of verb agreement. In: Cognitive Psychology $43: 83-128$. 
Coulson, Seana-Jonathan King-Marta Kutas 1998. Expect the unexpected: Event related brain response to morphosyntactic violations. In: Language \& Cognitive Processes 13:21-58.

Deutsch, Avital-Shlomo Bentin 2001. Syntactic and semantic factors in processing gender agreement in Hebrew: Evidence from ERPs and eye movements. In: Journal of Memory \& Language $45: 200-24$.

Friederici, Angela D. - Karsten Steinhauer-Stefan Frisch 1999. Lexical integration: Sequential effects of syntactic and semantic information. In: Memory and Cognition $27: 438-53$.

Guillelmon, Delphine-François Grosjean 2001. The gender marking effect in spoken word recognition: The case of bilinguals. In: Memory and Cognition 29:503-11.

Gunter, Thomas C. - Angela D. Friederici-Herbert Schriefers 2000. Syntactic gender and semantic expectancy: ERPs reveal early autonomy and late interaction. In: Journal of Cognitive Neuroscience $12: 556-68$.

Gurjanov, Manojlo-Georgije Lukatela-Jasmina Moscovljević-Milan Savić-Michael Turvey 1985. Grammatical priming of inflected nouns by inflected adjectives. In: Cognition 19:55-71.

Hyönä, Jukka-Raymond Bertram-Alexander Pollatsek 2004. Are long compounds identified serially via their constituents? Evidence from an eye-movement contingent display change study. In: Memory and Cognition 32:523-32.

Hyönä, Jukka - Johanna Lindeman 1994. Syntactic context effects on word recognition: A developmental study. In: Scandinavian Journal of Psychology 35 :27-37.

Hyönä, Jukka-Richard Olson 1995. Eye fixation patterns among dyslexic and normal readers: Effects of word length and word frequency. In: Journal of Experimental Psychology: Learning, Memory, and Cognition 21:1430-40.

Hyönä, Jukka - Alexander Pollatsek 1998. Reading finnish compound words: Eye fixations are affected by component morphemes. In: Journal of Experimental Psychology: Human Perception \& Performance $24: 1612-27$.

Juhasz, Barbara-Alexander Pollatsek - Jukka Hyönä-Denis Drieghe-Keith Rayner 2009. Parafoveal processing within and between words. In: Quarterly Journal of Experimental Psychology 62:1356-76.

Just, Marcel-Patricia Carpenter 1980. A theory of reading: From eye fixations to comprehension. In: Psychological Review $87: 329-54$.

Laine, Matti-Jussi Niemi-Päivi Koivuselkä-Sallinen-Jukka Hyönä 1995. Morphological processing of polymorphemic nouns in a highly inflecting language. In: Cognitive Neuropsychology 12:457-502.

Laine, Matti-Seppo Vainio-Jukka Hyönä 1999. Lexical access routes to nouns in a morphologically rich language. In: Journal of Memory and Language 40:109-35.

Laine, Matti-Patrik Virtanen 1999. Wordmill, Lexical search program. Centre for Cognitive Neuroscience, University of Turku, Turku.

Lehtonen, Minna-Matti Laine 2003. How word frequency affects morphological processing in monolinguals and bilinguals. In: Bilingualism: Language and Cognition $6: 213-25$. 
Lehtonen, Minna - Victor Vorobyev - Anna Soveri-Kenneth Hugdahl-Terhi Tuokkola - Matti Laine 2009. Language-specific activations in the brain: Evidence from inflectional processing in bilinguals. In: Journal of Neurolinguistics 22 :495-513.

Lukatela, Georgije - Milan Savić - Alexandar Kostić - Dejan Todorović - Claudia Carello-Michael Turvey 1987. Type and number of violations and the grammatical congruency effect in lexical decision. In: Psychological Research 49:37-43.

MacWhinney, Brian - Csaba Pléh 1997. Double agreement: Role identification in Hungarian. In: Language and Cognitive Processes 12:67-102.

Nicol, Janet-Kenneth Forster-Csaba Veres 1997. Subject-verb agreement processes in comprehension. In: Journal of Memory and Language 36 : 569-87.

Niemi, Jussi-Matti Laine-Juhani Tuominen 1994. Cognitive morphology in Finnish: Foundations of a new model. In: Language and Cognitive Processes 9:423-46.

Osterhout, Lee-Linda Mobley 1995. Event related brain potentials elicited by failure to agree. In: Journal of Memory and Language 34:739-73.

Pearlmutter, Neal J.-Susan M. Garnsey-Kathryn Bock 1999. Agreement processes in sentence comprehension. In: Journal of Memory and Language 41:427-56.

Rayner, Keith 1998. Eye movements in reading and information processing: 20 years of research. In: Psychological Bulletin 124:372-422.

Rayner, Keith-George W. McConkie 1976. What guides a reader's eye movements? In: Vision Research 16:829-37.

Schriefers, Herbert-Angela D. Friederici-Uwe Rose 1998. Context effects in visual word recognition: Lexical relatedness and syntactic context. In: Memory and Cognition $26: 1292-303$.

Vainio, Seppo-Jukka Hyönä - Anneli Pajunen 2003. Facilitatory and inhibitory effects of grammatical agreement: Evidence from readers' eye fixation patterns. In: Brain and Language 85 : 197-202.

Vainio, Seppo-Jukka Hyönä-Anneli Pajunen 2008. Processing modifier-head agreement in reading: Evidence for a delayed effect of agreement. In: Memory and Cognition $36: 329-40$.

Vilkuna, Maria 1989. Free word order in Finnish: Its syntax and discourse functions. SKS, Helsinki.

Virtanen, Patrik-Anneli Pajunen 2000. ContextMill [Computer software]. General Linguistics, University of Turku. 